\title{
Exploration and Construction of Teaching Quality Evaluation System
}

\author{
Xiuhong Zhang, Jie Wang, Donghai Su, Kai Zhang \\ School of Mechanical Engineering \\ Shenyang University of Technology \\ Shenyang 110870, China \\ zhangxh67@126.com, wangjiegd123@sina.com, shudh@sut.edu.cn, zhangkai@sut.edu.cn
}

\begin{abstract}
The teaching quality evaluation is an important part for judging teaching effect. How to establish a set of scientific teaching quality evaluation system has always been a problem concerned by education administrators and teachers. The guiding ideology, evaluating content and evaluating mode of the evaluation system have been discussed, and the teaching quality evaluation system has been established with the fourlevel self-evaluation subsystem. The results indicate that a set of scientific and reasonable evaluation system can promote teaching development, improve teaching quality, and ensure evaluating effect.
\end{abstract}

Keywords- teacher and student; teaching quality; evaluation system; exploration and construction

\section{INTRODUCTION}

Teaching is the common working center in university, and is the fundamental approach to cultivate talent and realize educational goal. Teaching quality evaluation of teacher is the important measure and assurance to achieve this approach, is the main power to highlight the central status and function of teaching, is the main method to scientifically evaluate teaching quality of teacher, and is the effective measure to prompt and lead teachers to improve teaching method, enhance professional level, and ensure teaching quality [1-3]. The level of teaching quality of teacher is directly related to the teaching effect, so how to estimate teaching quality of teacher and establish scientific teaching quality evaluation system seems particularly urgent. In order to ensure the science, just, fair and maneuverability of teaching quality evaluation work, the feasible teaching quality evaluation method should be formulated in accordance with the characteristic of university and school, thus improving teaching quality evaluation system constantly [4-6].

\section{GUIDING IDEOLOGY OF TEACHING QUALITY EVALUATION SYSTEM}

\section{A. Objective and Task of Teaching Quality Evaluation}

The primary objective of teaching quality evaluation is to impart suitable phased evaluation conclusion to teaching quality and level of teacher through scientific and precise evaluation means, cause teacher to gain synthetic and comprehensive feedback information so as to opportunely improve teaching through developing evaluation process, and provide the main basis for position promotion and professional and technical titles appraisal, produce correct guidance and stimulant function, motivate the teaching activity, promote the reform of teaching content and method, and further enhance teaching quality through effective teaching quality evaluation, and promote the teacher's ability of classroom lecture, improve the effect of classroom teaching, establish right teaching style and study style, and ensure classroom teaching quality through reinforcing the process management of classroom teaching.

The main tasks of teaching quality evaluation include: carry out teaching reform spirit, consolidate teaching reform effect; monitor teaching process, find and resolve the main problems that influence teaching quality in the teaching process in time, accelerate and drive the increase of classroom teaching quality, and improve the classroom lecture level of teacher and the design and assignment of teaching links; stimulate teachers to ameliorate teaching work, motivate the activity of teachers to engage teaching work, and deliver, communicate, feedback teaching information; construct the communication bridge between teachers and students, actually play the feedback, correction, stimulation, evaluation and drive function, strengthen the pertinence and the practice of education.

\section{B. Principle of Teaching Quality Evaluation}

\section{1) Guiding principle.}

Insist on putting the constant and correct policy direction in the first place, comprehensively assessing the basic quality of teacher; Persist in synthetically examining the educational quality of teacher according to the guidance of proper education thought.

2) Objectivity principle.

Insist on observing the problems with the developing insight, dialectically appraising the teaching effect of teacher; Persist in the viewpoint of unification between teaching and learning, and assess the teaching process of teacher and student. Strict operation procedure and serious evaluation discipline can ensure the reliability of evaluation results.

3) Maneuverability principle.

It is necessary to ensure the simplicity and concision of evaluation system, the science and precision of evaluation index, the conciseness and concretion of evaluation content, and the convenience and rapidity of evaluation method.

4) Combined principle between quantification and qualification. 
The result of quantitative evaluation is intuitive, is facile to fulfill data process, and is beneficial to promote the evaluation accuracy. However, due to the complexity of teaching activities, some contents are infeasible to quantify, but these contents substantially affect the teaching process. Accordingly, the method combining qualification and quantification should be adopted, which can ensure that the questionnaire include both subjective and objective evaluation section. Students and teachers can give the evaluation grade to assessed teachers through objective evaluation section, while propose the wish and shortage to them through subject one, so the synthetic evaluation is completed.

\section{EVALUATION CONTENT OF TEACHING QUALITY EVALUATION SYSTEM}

Evaluation content is critical to the teaching quality of teacher, and is also the quality monitoring factor of the whole teaching process. In fact, it is the extraction of working content of the whole teaching process. According to the analytical hierarchy process, the appraisal content of teaching activity is commonly classified into: teaching idea, teaching quality, teaching activity, teaching method, teaching means, teaching link arrangement, teaching effect, etc. In accordance with the general classification, the various qualities of teachers have been considered, so the detailed regulations of evaluation content can be obtained at last.

\section{EVALUATION METHOD OF TEACHING QUALITY EVALUATION SYSTEM}

The scale and network development of university is destined to waken the advent of quality evaluation system of network teaching. This can not only take full advantage of the existing network and teaching resource of university, and fulfill the data acquisition through campus network, but also obviously save time and cost, and fully embody just, fair and science.

The teaching quality evaluation adopts the method which combines students' teaching evaluation with experts' appraisement, and puts the former in the primary place, and the latter in the auxiliary one. Utilizing the existing teaching data resource of university, it should be guaranteed that every student can objectively appraise teacher with the acquaintance to him based on the careful learning. The teachers in the same trade are treated as specialist each other. They propose the appraisement to certain teacher through attending lecture and regular acquisition.

The students' evaluation includes the appraisement of common student and student leader. The students are treated as the object of teaching work service, and are the main partners in the teaching activities. They can sense the quality and ability of teachers in the process of continuous study. Thus, the evaluation of students is the main approach to reflect the level of teachers' teaching. The students are the main body of evaluation, and account for the major weight of teaching quality evaluation. Nevertheless, the appraisements of students commonly carry with the subjectivity. If the evaluation of teacher's teaching quality is completely performed by the students' evaluation results, it is hard to make it with absolutely justice. In order to resolve this problem, the evaluation system can specially propose the evaluation data of student leads as another important index. Compared with the common students, the student leaders possess the relatively high comprehensive quality, so their subjectivity and prejudice are smaller, and the evaluation results are comparatively subjective.

The teachers' evaluation is classified as peer teacher evaluation and leader evaluation. The teachers all possess the relatively high comprehensive quality, teaching level, and special knowledge. They have certain mental evaluation standard to the teaching methods and means of peer teachers, so the evaluation of peer teachers can not be ignored. In comparison with the evaluation weight of students, although the evaluation of peer teachers account for the relatively low evaluation weight, the teachers possess the subjectivity and prejudice. In order to improve this situation, the evaluation system can take the leaders' evaluation data as the fourth index. The school leader can synthetically consider this problem, and give the teachers' whole evaluation through the comprehensive index.

According to the four kind of evaluation methods: common students' evaluation, student leaders' evaluation, peer teachers' evaluation and teacher leaders' evaluation, the evaluation system can provide the last evaluation results by comprehensively considering the different weights, and adequately exhibit the objectivity of quality evaluation.

\section{CHARACTERISTICS OF TEACHING QUALITY EVALUATION SYSTEM}

1) Share and employ existing college resource.

The existing teachers' base, students' base, and teaching task data can be adequately employed, so the democratic evaluation of teachers' teaching quality can be realized without additional investment.

2) Network acquisition of evaluation data.

Landing any network interconnecting computer, the appraisers can mark the teachers with every item according to the specific evaluation index, and input the advice of students toward courses or teachers. Finally, the server will collect, count, and process the data, and ensure that the data can not be leaked or revised by people.

3) Set various evaluation indexes and count analysis data scientifically

The diverse evaluation index contents can be set, and the different weights can be set in accordance with the important degree of every index. The evaluation information for teachers are scientifically counted and analyzed, and evaluation data are analyzed and processed through statistics knowledge, and the advice and message for teachers by appraiser are printed.

4) Process various evaluation types simutaneously.

The evaluation data from different levels (college leader, peer teacher expert, common student and student leader, etc) can be automatically disposed. The synthetic grade is figured out according to different weights, and the teaching 
condition of teachers can be comprehensively reflected from diverse viewpoints.

5) Fair, justice, and objectivity.

Employing the form that students and teachers land with real name but mark with anonymity, the students land the marking system through student number and password, and choose the corresponding course to evaluate teacher; the teachers land the marking system through username and password, and choose the acquainted peer teachers to appraise. In order to guarantee the reasonability and justice of evaluation, the evaluation system is open before the final examination, which can decrease the situation that the students revenge teacher during evaluation because of the non-ideal examination score. The anonymous evaluation can eliminate the worry of students, and avoid the evaluation error due to the acquaintance each other, which can sufficiently embody the human-oriented idea.

\section{CONSTRUCTION OF TEACHING QUALITY EVALUATION SYSTEM}

University teaching is a complex system project, and this system has obvious hierarchy. The situation of teachers' teaching and students' study is a reflection of the quality of a course, and the qualities of diverse courses reflect the teaching quality of a discipline, major and college. In addition, the various teaching qualities of a discipline, major and college also reflect the whole teaching quality of university. Accordingly, the structure integrated level by level consists of the four-level self-evaluation subsystem: teacher teaching quality, course teaching quality, department teaching quality, and university teaching quality, as shown in Figure 1.

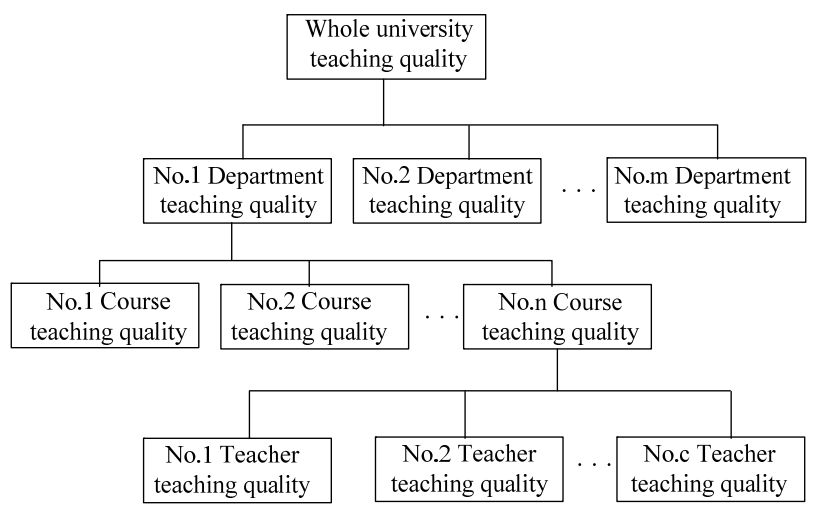

Figure 1. Structure of teaching quality evaluation system

\section{PRACTICAL EXPERIENCE OF TEACHING QUALITY EVALUATION SYSTEM}

1) According to the aim "People first, servicing teacher, servicing education", the enough evalution space should be provided for teachers and students, and avoid giving the students and teachers more pressure.

At present, the teaching evaluation is usually the rigidly arranged task that is proposed by leader, so the students and teachers are both in passive position. Consequently, the working method and thought should be innovated, and the teachers and students can be encouraged to carry out the teaching quality evaluation and feedback the information in time. The teachers should actively perform the research on teaching reform and teaching method, strengthen communication, and promote the teaching quality together.

2) The content of teaching quality evaluation should be suitable.

Not only considering the evaluation ability of students and projecting the mainbody function of students' study, but also considering the traits of different disciplines and courses. The teaching attitude of teachers, the difficulty degree of course, the influence of course on students, the communication between teachers and students should be emphasized. The evaluation content should scientific, reasonable, facile, and operable. The different evaluation indexes can be arranged for different appraisers, so as to enhance the authenticity and reliability of evaluation.

3) The organization and administration system of evaluation is strict and the propaganda is fittable.

It should be ensured that the students and teachers authentically know the purpose, method and significance, and deal with the evaluation with responsible attitude. Meanwhile, it should be ensured that the evaluation experts and students possess the absolutely independent evaluation space. The emotion factor of peer experts in the evaluation process, and the evaluation error originated from the prejudice of students to teachers should be avoided.

4) The evaluation result is disposed corretly and reasonably.

After the evaluation, the system administrator timely counts result and announce it through network, and the teachers and students can examine the evaluation result through the landing username and password. The teachers refer to evaluation result, comprehensively acquaint myself, shoot the arrow toward the target, continuously develop the merits, find out the shortcoming, and then give more attention. According to the situations reflected by students and teachers, timely management, resolution, and feedback can make the evaluation significance manifest authentically.

\section{CONCLUSIONS}

In general, the teaching quality evaluation is the critical part of the college teaching management, and is a relatively complicated system project. The teaching quality evaluation system could be suitably established with the four-level selfevaluation subsystem. The evaluation is not the intention, but the important means to appraise teaching, promote teaching development, and improve teaching quality. The scientific and reasonable teaching quality evaluation system fully plays the role in teaching quality appraisement, makes the evaluation effects distinct and significant, and achieves the aim to completely promote teaching quality. 


\section{ACKNOWLEDGMENT}

This research is supported by the General Program of Education and Science of Liaoning Province during the 12th Five-Year Plan Period, No. JG11DB207.

\section{REFERENCES}

[1] Y.K. Chen. “Teaching Evaluation”, Beijing: People's Education Press, 1999.

[2] L. Yu. “Classroom Teaching Assessment”, Beijing: People's Education Press, 2007.

[3] Z.R. Du, W.W. Liao. "Higher Education", Shanghai: Fudan University Press, 2003.
[4] Y. Lu. "A Study on Constructing a Quality Assurance System for Undergraduate Teaching at Regular Higher Institutions: Illustrated with the Case of E University”, East China Normal University, 2007.

[5] J.H. Hong. "Strengthening Experimental Teaching Supervision, Improving Personnel Training Quality” , Experiment Science \& Technology, 2009(6).

[6] H.Q. Jing, J. Li, B.J. Zhao. "Fulfilling Function of Teaching Supervision to Improve Teaching Quality of Higher Education", China Higher Medical Education, 2010(1) 